\title{
Correction to: A Genetic Investigation of the Well-Being Spectrum
}

\author{
B. M. L. Baselmans ${ }^{1,2}$ (1) M. P. van de Weijer ${ }^{1,2} \cdot$ A. Abdellaoui ${ }^{1,5} \cdot$ J. M. Vink ${ }^{3} \cdot$ J. J. Hottenga ${ }^{1} \cdot$ G. Willemsen ${ }^{1}$. \\ M. G. Nivard ${ }^{1}$ - E. J. C. de Geus ${ }^{1,2,4} \cdot$ D. I. Boomsma ${ }^{1,2,4} \cdot$ M. Bartels ${ }^{1,2,4}$
}

Published online: 21 March 2019

(C) Springer Science+Business Media, LLC, part of Springer Nature 2019

\section{Correction to: Behavior Genetics https://doi.org/10.1007/s10519-019-09951-0}

In the original version of this article, unfortunately, in the acknowledgement section "National Institutes of Health (NIH, R37 AG033590-08) to J Cacioppo" was omitted. This has been corrected by publishing this erratum.

Publisher's Note Springer Nature remains neutral with regard to jurisdictional claims in published maps and institutional affiliations.

The original article can be found online at https://doi.org/10.1007/ s10519-019-09951-0.

B. M. L. Baselmans

b.m.1.baselmans@vu.nl

1 Department of Biological Psychology, Vrije

Universiteit Amsterdam, Van der Boechorststraat 1, 1081 BT Amsterdam, The Netherlands

2 Amsterdam Public Health Research Institute, Amsterdam, The Netherlands

3 Behavioural Science Institute, Radboud University, Nijmegen, The Netherlands

4 Neuroscience Amsterdam, Amsterdam, The Netherlands

5 Department of Psychiatry, Amsterdam University Medical Centre, Location Academic Medical Center, Amsterdam, The Netherlands 